«Системні технологіï» 6 (131) 2020 «System technologies»

DOI 10.34185/1562-9945-6-131-2020-01

УДК 621.454.2.046.4+621.22:678

А.В. Литот, Т.А. Манько

\title{
МОДЕЛИРОВАНИЕ МНОГОСЛОЙНОГО КОМПОЗИЦИОННОГО МАТЕРИАЛА ФЛАНЦА ТОПЛИВНОГО БАКА ИЗ УГЛЕПЛАСТИКА
}

Аннотация. Статья посвящена сравнительной оценке компьютерного моделирования процесса укладки многослойного композиционного материала сложной формы и его практического исполнения на примере фланца топливного бака из углепластика. Проведен микроструктурный анализ материала фланца топливного бака и формирования многослойной конструкции. Оценен уровень и размеры укладки наполнителя при сохранении плоскостности и взаимного положения отдельных слоев композиционного материала большой толщины. Представлены оценка полученных результатов и сформулированы выводы по работе. Ключевые слова: углепластик, фланец топливного бака, микроструктурный анализ, технология изготовления ПКМ.

В настоящее время создание элементов ракетно-космической техники из полимерных композиционных материалов требует понимания не только особенностей материалов, а и технологии их изготовления. Это связано с тем, что в деталях из композиционных материалов (KM) - материалы, конструкция и технология являются неотъемлемой частью друг друга [1]. Как одним из методов оценки целесообразности выбора конструктивно-технологических решений и технологических приемов, принятых при изготовлении, являются микроструктурные исследования технологических или опытных образцов.

Объектом исследований является фланец опытной конструкции топливного бака после проведения циклических испытаний избыточным давлением воды, жидкого азота и произошедшего разрушения силовой оболочки. Конструктивно фланец выполняет роль формообразующей поверхности при намотке силовой оболочки топливного бака в зоне полюсных отверстий, и обеспечивает взаимное скрепление встык с крышкой [Рис 1] . Он выполнен из углепластика, изготовленного методом формования в жесткой форме на основе высокопрочной углеродной ткани 3752 двунаправленного (равнопрочного) полотняного плетения и эпоксидного связующего.

(C) Литот А.В., Манько Т.А., 2020 
«Системні технології» 6 (131) 2020 «System technologies»

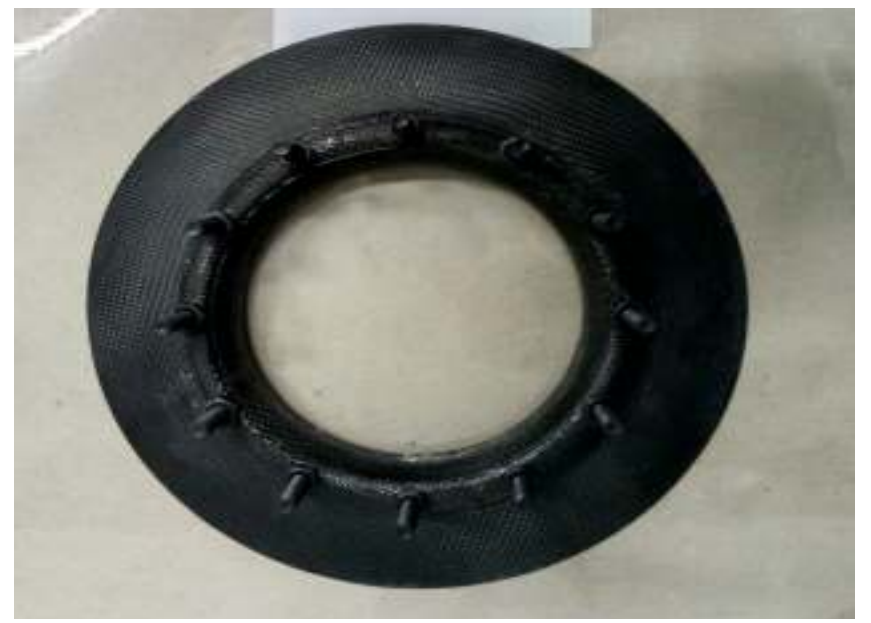

Рисунок 1 - Фланец топливного бака в сборе

(с установленными элементами металлического крепежа)

Учитывая высокую сложность геометрии фланца и большое количество слоев, подлежащих укладки, при его проектировании применяли средства компьютерного моделирования для большинства рабочих операций. Как результат, геометрия углепластиковой заготовки фланца получена путем поочередной укладки 74 слоев, 18 из которых формирует силовое перо фланца, со схемой армирования [0/+45]n (Рис. 2). При этом толщина углепластика в зоне полюсного обода фланца достигает 20,5 мм.

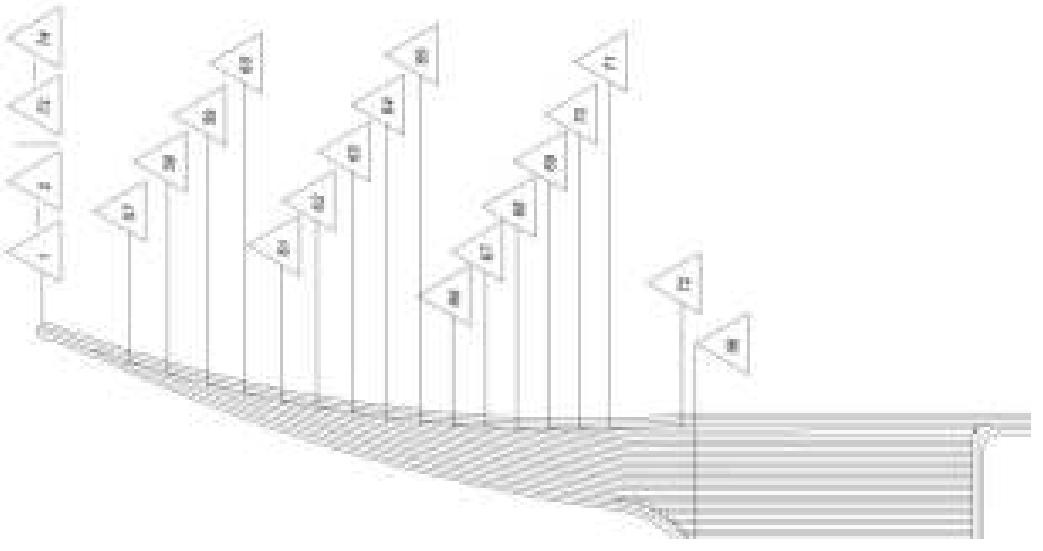

Рисунок 2 - Схема укладки слоев для формирования основной геометрии фланца из углепластика

Для исследования зоны силового пера фланца на разных его участках использовали торцевые шлифы вырезанных образцов из различных зон фланца. 
«Системні технології» 6 (131) 2020 «System technologies»

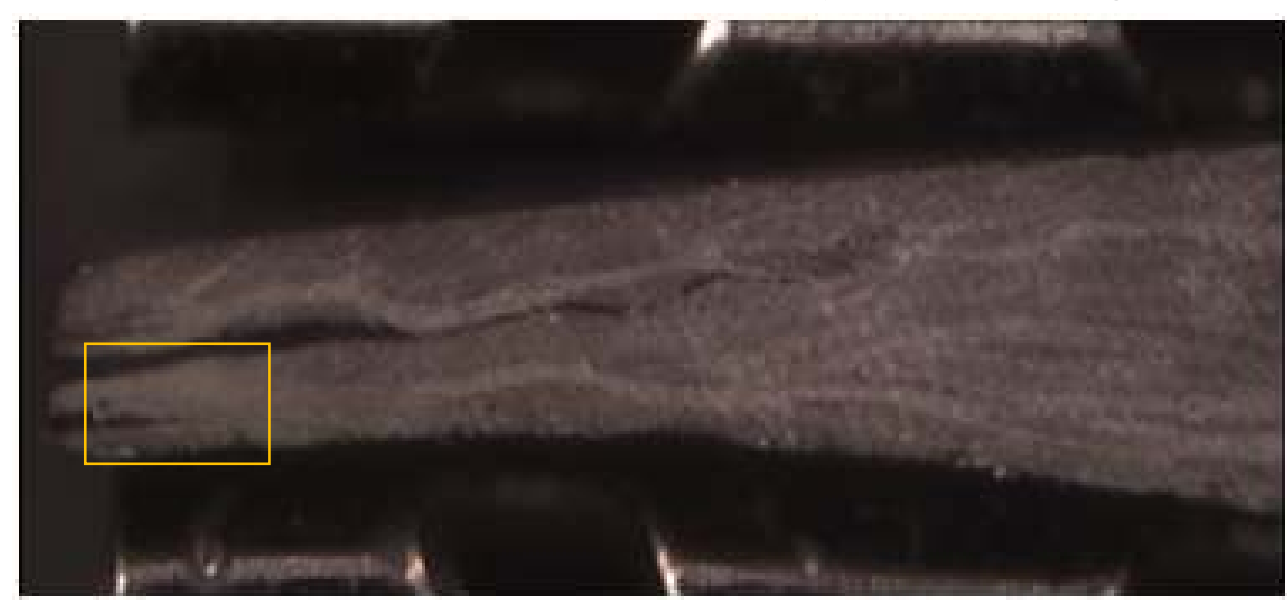

Рисунок 3 -Микроструктура исследования кромки пера фланца из углепластика (оптический режим)

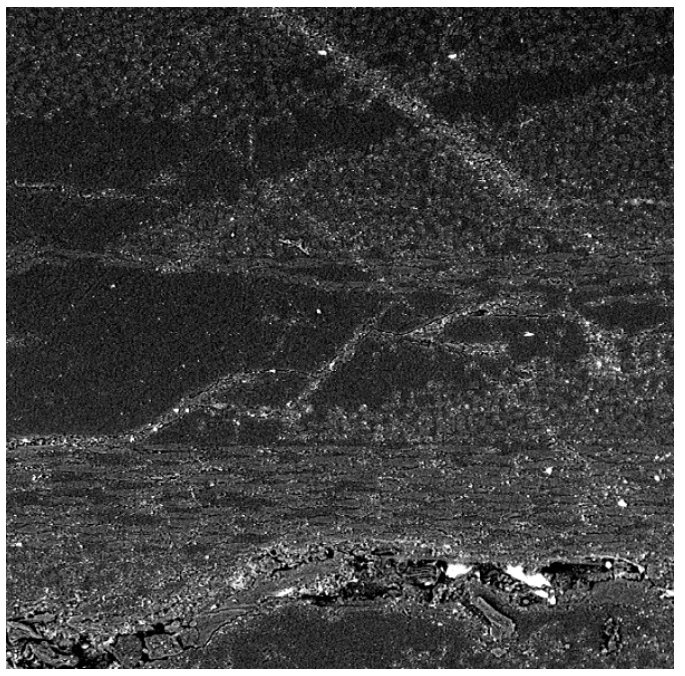

Рисунок 4 - Трещины в материале на кромке пера фланца

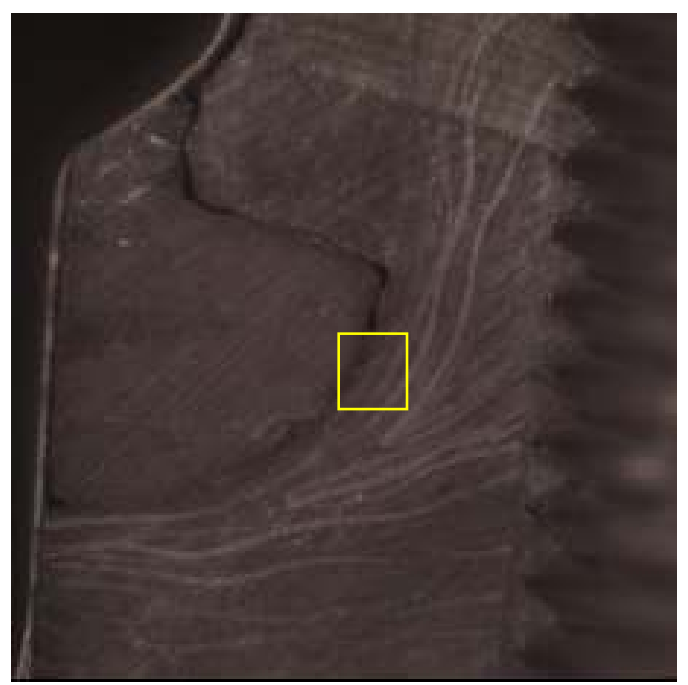

Рисунок 6 - Структура

утолщения фланца

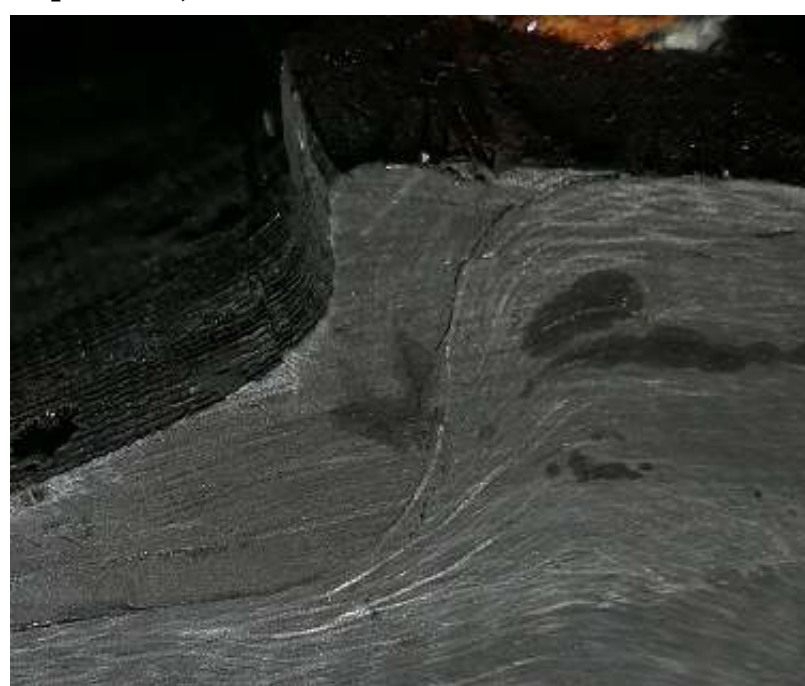

Рисунок 5 - Зона утолщения вокруг полюсного отверстия

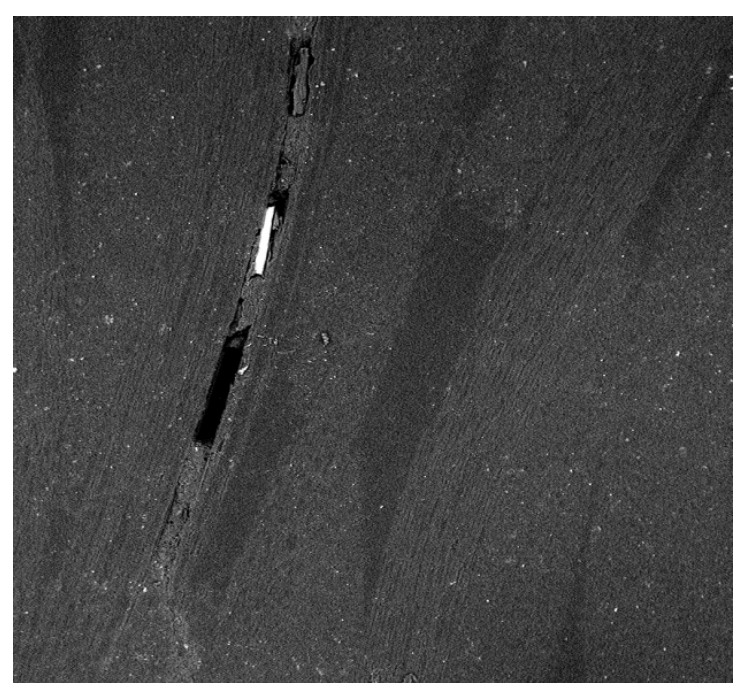

Рисунок 7 - Расслоение на границе с силовой оболочкой топливного бака 


\section{«Системні технології» 6 (131) 2020 «System technologies»}

Еще до выполнения исследований микроструктуры образцов вырезанных из фланца визуально наблюдалось расслоение кромки пера по всей его длине. Подробное исследование образцов показало, что расслоение произошло как межслоевое, на глубину не более 5 мм, так и с образованием трещин, проходящих через продольные волокна ткани с прерыванием на поперечнопересекающих волокнах(Рис. 3, 4).Такие дефекты структуры несут единичный характер, длиной, не превышающей 1 мм, и образованы в местах выполнения подрезки продольных волокон выполненной при обрезке технологического припуска. Все наблюдаемые структурные разрушения кромки пера фланца произошли при давлении, превышающей рабочее более чем в 4 раза и не сказались на работоспособность конструкции в целом (разрушение конструкции топливного бака произошло по цилиндрической части с развитием трещин, не пересекающих зону пера). Эти разрушения на герметичность конструкции топливного бака повлиять не могут и образованы непосредственно в процессе испытания или в момент разрушения конструкции.

Также большой интерес представляет исследование зоны утолщения фланца вокруг полюсного отверстия. При этом основное внимание обращалось как на качество заполнения клеевого зазора вокруг металлических крепежных элементов, так и оценка качества формования материала и сохранение плоскостности уложенных слоев (Рис. 4,5 ). Ввиду особенности структуры ткани выделить и подтвердить расчетную толщину монослоя затруднительно [4]. Засвеченные единичные продольные волокна плетения ткани позволили сделать вывод, что для вероятно первых нескольких слоев силовой части пера, принятых в схеме как 57-60 слой, имеют отклонение от плоскости перпендикулярной оси фланца с последующим выравниванием. Остальные слои силовой части пера в большей своей части сохраняют плоскостность.

В дополнение, при проведении анализа обнаружено возможное межслойное разрушение обода фланца, повлекшее за собой потерю герметичности при давлениях, предшествующим критическим. Их образование, вероятно, произошло из-за подрезки обобщающих слоев № 1,2 для выполнения установки уплотнения(Рис. 5).

Немаловажной частью такого рода анализа является исследование укладки и кластерных структур материала [5]. Это обусловлено необходимостью оценки влияния на структуру композита как режимов отверждения, проходящих при дальнейшем отверждении силовой оболочки, так и влияния криогенных температур неизбежно разрушающий композиционный материал на мик6 


\section{«Системні технологіï» 6 (131) 2020 «System technologies»}

роструктурном уровне. Нарушения сплошности, как в первом, так и во втором случае обусловлены огромной разницей коэффициента линейного температурного расширения материала матрицы и наполнителя. Так, для принятой эпоксидной матрицы значение находится в диапазоне от 22 до 55 K-1×10-6, а для углеродного наполнителя порядка $0.08 \pm 0.12 \mathrm{~K}-1 \times 10-6$. В уже сформированном композиционном материале значение коэффициента линейного температурного расширения сводится к высокой жесткости наполнителя и принимает значение 2.86-3.12 K-1×10-6 для перекрестного армирования. При этом, такое характерное поведение композита наблюдается лишь в направлении армирования, и значение в направлении перпендикулярном плоскости армирования равно значению для матрицы.

Подробное исследование структуры слоистого углепластика показало, что в аморфном состоянии созданы четко выраженные упорядоченные надмолеколярные структуры. Для обеспечения надмолекулярной организации аморфных полимеров использована кластерная модель. Под кластерами будем понимать области, у которых есть упорядоченные или организованное расположение структуры единиц композита по сравнению с другой аморфной частью. Отличительной чертой кластерной модели является то, что в ней не регламентируется характер морфологии цепей внутри кластера. В данной материале эпоксидном полимере кластер состоит из макромолекул, имеющих складчатую конформацию, что хорошо согласуется с моделью Иеха. [3] Разница в плотностях упорядоченных структур неупорядоченных областей не превышает 1,5\% (у кристаллического полимера эта разница достигает 30\%). Эти структуры окружены приграничной областью и сосредоточенны, преимущественно, в центрах больших конгломераций.

Выводы: Исследование микроструктуры образцов многослойного композиционного материала большой толщины позволило оценить уровень и равномерность укладки наполнителя, сохранение плоскостности и взаимного положения отдельных слоев и качество формования всего пакета. Проведенные исследования на образцах, вырезанных из корпуса прошедшего разрушения, показало развитие трещин и дефектов в зоне кромки пера и подрезки под уплотнение. Возможным решением является уменьшение толщины кромки пера для увеличения ее деформативности и увеличения количества обобщающих слоев для улучшения сдерживания всего пакета. 


\section{«Системні технології» 6 (131) 2020 «System technologies»}

\section{ЛИТЕРАТУРА / ЛІТЕРАТУРА}

1. Гагауз П.М., Гагауз Ф.М., Карпов Я.С., Кривенда С.П. Проектирование и конструирование изделий из композиционных материалов. Теория и практика: учебник/ П.М.Гагауз, Ф.М.Гагауз, Я.С.Карпов, С.П.Кривенда; под. общ. ред. Я.С.Карпова - Х.: Нац. аэрокосм. ун-т им. Н.Е.Жуковского, 2015 - 672 с.

2.Карпов Я.С.Проектирование деталей и агрегатов из композитов: учебник/Я.С. Карпов. - Х.: Нац. аэрокосмич. ун-т "Харьк. авиац. ин-т", 2010. - 768 с.

3. Манько Т.А., Гусарова И.А., Роменская О.П., Самусенко А.А., Деревянко И.И., Эксперементальное иследование свойств углеродных композиционных материалов на трубчатых моделях. Космическая наука и технология. Вып. 4, Tом 26. 2018. - 59-63c.

4.Карпов Я.С. Соединения деталей и агрегатов из композиционных материалов / Я.С. Карпов. - Х.: Нац. аэрокосм. ун-т им. Н.Е.Жуковского, 2006 - 359 с.

5.YehG.S. J.Macromol. Sci., 1972. B.v. 6(3), p. 465-478.

\section{REFERENCES}

1. Gagauz P.M., Gagauz F.M., Karpov Ya.S., Krivenda S.P. Proektirovanie i konstruirovanie izdeliy iz kompozitsionnyih materialov. Teoriya i praktika: uchebnik/ P.M.Gagauz, F.M.Gagauz, Ya.S.Karpov, S.P.Krivenda; pod. obsch. red. Ya.S.Karpova - H.: Nats. aerokosm. un-t im. N.E.Zhukovskogo, 2015 - 672 s.

2.Karpov Ya.S. Proektirovanie detaley i agregatov iz kompozitov: uchebnik/Ya.S. Karpov. - H.: Nats. aerokosmich. un-t "Hark. aviats. in-t", 2010. - 768 s.

3. Manko T.A., Gusarova I.A., Romenskaya O.P., Samusenko A.A., Derevyanko I.I., Eksperementalnoe isledovanie svoystv uglerodnyih kompozitsionnyih materialov na trubchatyih modelyah. Kosmicheskaya nauka i tehnologiya. Vyip. 4, Tom 26. 2018. 59-63s.

4.Karpov Ya.S. Soedineniya detaley i agregatov iz kompozitsionnyih materialov / Ya.S. Karpov. - H.: Nats. aerokosm. un-t im. N.E.Zhukovskogo, 2006 - 359 s.

5.YehG.S. J.Macromol. Sci., 1972. B.v. 6(3), r. 465-478.

Received 02.11.2020. Accepted 05.11.2020.

\section{Моделювання многошарового композиційного матеріалу фланцю паливного баку із вуглепластику}

Стаття посвячена порівняльній оцінці комп'ютерного моделювання процесу викладки многошарового композиційного матеріалу складної конфігурації і його практичного виконання на прикладі фланця паливного баку із вуглепластику. Проведений мікроструктурний аналіз матеріалу фланцю паливного баку і формування многошарової конструкції. Оцінений рівень і розміри викладки наповнювача при збереженні площинності і взаємного положення окремих шарів композиційного матеріалу великої товщини. Представлена оцінка отриманих результатів і сформульовані висновки до роботи. 
«Системні технологіï» 6 (131) 2020 «System technologies»

Modeling of a multi-layer composite material of a fuel tank flange from cfrp

The article is devoted to the comparative assessment of computer modeling of the process of laying a multilayer composite material of complex shape. It also discusses a practical implementation using the example of a CFRP fuel tank flange. The analysis of the microstructural material of the fuel tank flange and the resulting multilayer structure is carried out. The level and dimensions of the filler packing are estimated while maintaining the flatness and mutual position of individual layers of a composite material of great thickness. Studies carried out on specimens cut from the assembly after failure have shown the nature and features of the failure of the flange material. A possible solution is proposed to eliminate such problems and to increase the deformability of the flange, which ensures joint operation with the supporting shell. An assessment of the results obtained is presented and conclusions on the work are formulated.

Литот Александр Владимирович - инженер 1 категории Государственного Предприятия «Конструкторское Бюро «Южное» им. М.К. Янгеля.

Манько Тамара Антоновна - д.т.н., профессор, профессор кафедры технологии производства ФТФ Днепровского национального университета имени Олеся Гончара.

Літот Олександр Володимирович - інженер 1 категорії Державного Підприємства «Конструкторське Бюро «Південне» ім. М.К. Янгеля.

Манько Тамара Антонівна - д.т.н., професор, професор кафедри технології виробництва ФТФ Дніпровського національного університету імені Олеся Гончара.

Litot Aleksandr - Engineer of the 1st category of the Yuzhnoye State Design Office. Man'ko Tamara - doctor of technical sciences, professor, professor of the department of production technology PTF Oles Gonchar Dnipro National University. 